\title{
Small is Beautiful...or Not?
}

by NOL VERHAGEN

\section{INTRODUCTION}

This paper explores recent developments within library organisations and their impact for the functioning of university libraries, and more specific, the relations between the central library and decentral libraries. Examples are taken from the University of Amsterdam, the author's home institution, and from the $\underline{\mathrm{UKB}}$, the consortium of Dutch Research libraries.

Founded in 1632, the University of Amsterdam in 2007 will enjoy its 350th anniversary. It is not the oldest university of the Netherlands, but still a respectable old lady! For a long time it was just a rather modest institution, but at the verge of the 20th century it experienced, like many other European universities, an impetuous growth, that after World War II even intensified. In the 60's and 70's, when Higher Education was democratised and the baby-boomers knocked at the doors, it became a really massive institution. In a city like Amsterdam, that lacked space for a university campus, this growth led to a splitting up of the university in an ever-increasing number of institutes, scattered all over the city.

Actually this development was not just a matter of housing. Developments in scientific research and teaching too contributed to the falling apart of the old faculties in ever smaller units, like subfaculties, institutes, seminaries and departments, each with their own housing, their own teaching staff, their own support staff, their own stencil machine and, yes indeed, their own library and their own librarian. In this world the Professor Director was his own king, and managers and governors had but little, if any, influence on academic teaching and learning.

Academic libraries therefore showed and still show in many places in the world, in Europe even more than elsewhere, a startling dichotomy: on the one hand a sometimes large central library, that not seldom hosts a respectable historic collection, but on the other hand a wide variety of institutional or faculty libraries, that with a high amount of independency serve a relatively small group of students and faculty. These institutional libraries were and are under the direction of professors rather than the university librarian.

\section{THE UNIVERSITY LIBRARY - A UNIVERSITY WIDE SYSTEM OF LIBRARIES}

This was still the case when I came to work at the University of Amsterdam, as Director of the Humanities Faculty, in 1990, although by then a counter development already had gained some strength. The Humanities Faculty for instance had moved into a restricted number of larger buildings, where the former institutional libraries had been brought together as well. In name there was an organisation that was called the faculty library, which however de facto mainly consisted of these former institutional libraries that still were claiming their independency and that only under high pressure were prepared to share such basic facilities as a common circulation desk. We have seen astonishing examples of this not working together. If it turned out to be so difficult to cooperate on a local level, how difficult it must have been with respect to the central library... However, in Amsterdam the university library from early days fulfilled central tasks in the fields of acquisition and cataloguing for all libraries.

In the last one or two decades much has changed. The reasons partly came from changes that took place in the organisational structures of the university itself: the small, semi-autonomous units were put together in larger units with more decision making powers: the faculties. In 1990 we had in Amsterdam still 15 faculties, now we have only 7 left. The number of faculty librarians therefore has dropped dramatically. Besides that, teaching and research is being organised in ever-wider patterns of relationships: researchers collaborate across the borders of departments, faculties, and even institutions, and the academic educational programmes are developing into ever more multi or interdisciplinary direction. Recently the development (on the Continent) towards the Anglo-Saxon Bachelor and Master structures, following the Bologna Declaration, played a part as well.

Even when we put aside the Digital Library, on which we will come back later, it's obvious that the days of small independent libraries are over, at least in a university setting. Nevertheless it was only 5 years ago, when the libraries of the University of Amsterdam decided to accept a common regulation for lending - until then each location maintained its own rules, what our users found hard to understand. Today we offer our users the opportunity to collect and deliver their books and periodicals at the library of their choice - the system manages the transportation of the volumes between the several locations. This would have been out of discussion only a few years ago. 
It goes without saying that the digitisation of the library services not only has facilitated these developments, but also that it has been an important driver of these developments. Digitisation enables us to serve our users much better en quicker than we used to. A restricted group of dedicated users, however, assess this as a decline: these users, mainly professors, formerly had a sort of authority over library affairs and could count on a special treatment by the library staff. Today, in Amsterdam it is the explicit ambition of the library to make the user self-supporting by making the library self-evident. Not just to enable savings on personal services by library staff, but also to make the library more attractive: for both parties it is supposed to be preferable if users can satisfy their needs on their own account, rather than having to rely on the support of a library staff member. But to be honest, this view is not yet shared by all library staff, nor by all users.

Earlier we said that the number of faculties and smaller units have decreased dramatically. The same is true for the number of library locations. In Amsterdam instead of some 200 library locations, we nowadays have about 20. Even in the last 5 or 6 years this number has dropped from 40 to 20. And it's my expectation that before 2010 we will end with less than 10. Of course it follows that the remaining libraries are by no means small libraries, but rather big or at least medium sized facilities, housing collections of at least some kilometres of shelving and tens or even hundreds of study places. Such a scale supposes at least some form of collaboration beyond the boundaries of institutes and faculties. The replacement of vast amounts of printed volumes alone, that inevitably accompanies this scaling up, needs central direction and coordination.

The University of Amsterdam has central book storage at its disposal at the outskirts of the town, which is used by all libraries of the university. In recent years all faculty libraries have achieved large scale deselecting operations, during which large amounts of printed materials have been moved from open shelves within the libraries to the central storage. In the last 6 years it was almost 16 kilometres of material that have been taken out of the open stacks and have been replaced in the storage. Not only the replacement itself requires a considerable amount of cooperation, making these volumes available for users from out of the storage requires this too. Actually it supposes that the library of physical items functions as a well-oiled machinery for the whole university. It makes the faculty libraries ever more dependent on the central library that controls the mutual systems and processes - and willingly or not, they'll become a sort of branch libraries within a university wide system of libraries.

Everybody knows this is true and necessary, and at the same time it is still not easy to realize this concept in every days practice. Universities, and therefore their libraries as well, strongly believe in the axiom that as much autonomy as possible should be delegated to the lowest possible level of the organisation - quite contrary to the general managers who believe that quality of service is enhanced by an appropriate division of tasks and powers, in which the lowest level should not exercise more power than is needed for its well functioning.

An important feature that prevents the library from functioning efficiently as a university wide system, is the worldwide tendency to define faculties as so called result responsible units, a concept that, unfortunately, has been transported from real business to the not for profit sector, where it is not always well understood, nor correctly implemented. By doing so, faculties are supposed to make their own policy and to be financially responsible for as many operations as possible: from teaching and learning to housing and libraries. Library budgets still are, in Amsterdam as well, allocated to faculties. This implies that faculty libraries are actually managed by faculty deans and that they have a fair amount of room to make their own decisions and choices in for instance the implementation of the digital library and digital services. Ironically we see problems - which we just have solved more or less in the physical library - return in the digital environment.

\section{THE DIGITAL LIBRARY - A CAMPUS WIDE SERVICE}

One of the hottest issues is the participation in license agreements. This is a faculty issue because the costs of it have to be paid from the faculty budgets. At the same time it's crystal-clear, that if in the management of the physical library cooperation is necessary, this is even truer with respect to the digital library and digital library services. In Amsterdam, and in all other Dutch universities that we know of, the digital library is conceived as a campus wide service, and the basic facilities for the digital information supply are made available by the central library. There's no other way, we think. After all, we use the university's campus wide network and we contract licenses for systems as well as content on behalf of the whole university, including the Academic Hospital, the latter not seldom causing its own set of problems. It's not realistic to suppose that the decentral level is capable to generate the expertise, the competence and the capacity that is needed to keep the system in the air and to maintain the necessary contacts with suppliers.

In Amsterdam we try to communicate these developments, and to generate the cooperation that is required, through an institutionalised consultation between the central library and the faculty libraries. Besides an ongoing process of cooperation and collaboration, we are facing an ongoing tension between these two levels as well. Faculty librarians (and their deans too) think, and not always without reason, that they know the needs of their users better than the 
central library, and they hate it being confronted with a university librarian, who sets the rules for them. Moreover, they often find the central library slow and bureaucratic and lacking flexibility. At the same time they not always sufficiently understand that running a campus wide facility is something else than maintaining a local, restricted, lean and mean proprietary application. Everyday practice however, learns that developments go so fast, that small, specific proprietary solutions, that faculty libraries sometimes develop, cannot keep up with them. Nevertheless it remains difficult and laborious to control the faculty libraries and to prevent them from finding their own solutions again and again, or from circumventing common approaches and facilities, or even from sabotaging them. But as you will be aware, this is nothing new ...

From the beginning of my career as a librarian, that, by the way, only started in 1997, I've emphasized the idea of a common university library, in which the central library and the faculty libraries cooperate to the best of their abilities and conceive themselves as members of one university wide organisation, even if the actual formal organisational structures may not fully reflect that concept. It requires not a small amount of convincing and even more balancing power, to keep that concept alive. One of the means we in Amsterdam use for that purpose is our so-called electronic database-consulting group. The university library has put a part of her budget at the disposal of this group for the financing of common licenses on electronic databases (most of them of bibliographic nature), and in fact the faculties can spend that money (some K€ 600 per year) within agreed restrictions and observing the rules of the game.

\section{BIG DEALS - CONSORTIUM LICENCES}

Another issue with respect to cooperation are the licensing agreements with publishers of scholarly information. As we all know, many libraries (among them all Dutch University Libraries) have left to a considerable extent the concept of title per title subscription on scientific journals some years ago. Today they enter licenses to so called big deals that include all or very many titles of scientific publishers. It goes without saying that all faculties of a university participate in these licenses and in the costs that follow from them. But it is even worse: these licenses usually are not agreed on by single universities, but by groups of universities, or even all universities within a certain area or country: that's what we call consortia. In some countries like Sweden, Finland and the UK, these consortia cover large groups of libraries and institutions with rather different background and nature, such as universities, polytechnics, research institutes and sometimes even public libraries. It's obvious that the management of the decision making process around these agreements is not always easy, and that's even more true, when such a consortium covers a greater number and a wider variety of participants.

Until recently the costs of these agreements for each participant were mainly based on their historic spending on printed journals. The transition to electronic only delivery makes it almost inevitable to introduce more balanced models for division of costs. That's why such a consortium not only must seek mutual agreement on the overall conditions for a contract, but also on the division of the costs of that contract among the participants. This is not the place to deal with this issue in detail, nor with the solutions we have developed for it in the Netherlands. But notice that the same issue, namely the division of costs, may put at risk the cooperation between the libraries within one university. After all the faculty libraries, which are almost excluded from the decision making itself, still have to pay the bill. They're just confronted with the results of the negotiations, both with the publishers and within the consortium.

In short, and again, the bright days for small independent subject libraries are over, unless they succeed in fulfilling very specific needs of a very specific group of users that is capable, and willing, to pay the relatively high price of that service. On the other hand, organising a university wide system of libraries is all but an easy job to do, because the organisational and financial structures are still highly decentralized. Nevertheless it's clear that the trend for the near future will be: more scaling up and more centralization. Our users don't bother about organisational structures. They just want a well-designed and well functioning service, both in the physical and the digital information supply. And if we cannot deliver, they'll use Google and Yahoo. They're using these anyway. So libraries will have to concentrate on what Google and Yahoo cannot do: give access to qualified content and add customer-oriented services to it. We think that we should not be afraid of Google, and even not of Google Scholar. In fact these search engines can help us to reach our users and to make them get what they need. Our own library for instance, has Google Scholar enriched with our SFX service, so that our users immediately are aware if a specific article, found in Google Scholar, is accessible for them in full text - and if so, with one mouse click they can gain access to that article and to the full service of the digital library. 


\section{THE CHALLENGE OF THE LIBRARY}

Fortunately we are still strong in document supply. A bit to my surprise lending statistics have increased by $30 \%$ during the last few years in Amsterdam. We're also information brokers, managing access to valuable content and content related services for our users - notice that we've been doing a very good job there, giving our patrons much better value for money, through big deals and electronic delivery, than they could ever have dreamt of. And we're service providers, always improving both physical and digital support for the primary processes in our universities and making not a small contribution to the effectiveness and efficiency of these processes. The irony is that we only can do so by organising the library as an enterprise wide service within a fundamentally decentralised environment.

\section{WEB SITES REFERRED TO IN THE TEXT}

Bologna Declaration of 19 June 1999. http://www.bologna-berlin2003.de/pdf/bologna_declaration.pdf

UKB, the consortium of Dutch Research libraries. http://www.ukb.nl/English/welkom.htm

Universiteit van Amsterdam. http://www.english.uva.nl/

University Library of the Universiteit van Amsterdam. http://www.uba.uva.nl/english/home.cfm 